\title{
Bilinçli Farkındalık Temelli Bilişsel Terapi Programının Obsesif Kompulsif Belirtiler Üzerindeki Etkisi
}

\author{
DOI: $10.26466 /$ opus.618175
}

\author{
$*$ \\ Nazire Ayşenur Gündoğan * - Gaye Saltukoğlu** - Melek Astar *** \\ *Uzm. Kl. Psk. İstanbul / Türkiye * \\ E-Posta: nazireayse@gmail.com \\ ORCID: Gümn \\ ${ }^{* *}$ Doç. Dr., Fatih Sultan Mehmet Vakıf Üni., Edebiyat Fakültesi, Üsküdar / İstanbul / Türkiye \\ E-Posta : gsaltukoglu@fsm.edu.tr \\ ORCID: 0000-0002-6249-6246 \\ ***Dr. Öğr. Üyesi, Fatih Sultan Mehmet Vakıf Üniversitesi, Edebiyat Fakültesi, İstanbul / Türkiye \\ E-Posta : $\underline{\text { mastar@fsm.edu.tr }}$ \\ ORCID: 0000-0001-5906-6184 \\ Öz
}

Görülme sıklığı her geçen yıl artan obsesif kompulsif bozukluğun belirtilerinin sağaltımında oldukça etkili bir psikoterapi yaklaşımı olan bilişsel davranışçı terapi, bilişsel terapilerin üçüncü dalgası olarak nitelendirilen bilinçli farkındalık yaklaşımlarının psikoterapi alanına dahil edilmesi ile literatürde önemli bir yere sahip olmuştur. Bu çalışmanın amacı, bilinçli farkındalık temelli bilişsel terapi programının bireylerin obsesif kompulsif belirtileri azaltmadaki etkisini incelemektir. Bu amaçla çalışma, kontrol gruplu ön-son-izlem olmak üzere tekrarlı ölçümler aracılığıyla deneysel bir çalı̧̧a olarak tasarlanmıştır. Veri toplama araçları olarak kişisel bilgiler için "Demografik Bilgi Formu", katılımo kriterlerini incelemek için SCL-90 Belirti Tarama Listesi ve deneyimlenen obsesif kompulsif belirti düzeyini belirlemek için Padua Envanteri kullanılmıştır. Elde edilen veriler gerekli varsayımlar să̆landıktan sonra Tekrarlı Ölçümler için İki Yönlü Varyans Analizi ile incelenmiş ve analiz sonucunda, müdahale grubuna uygulanan programın, katılımcılarm obsesif kompulsif belirti düzeylerinde istatistiksel olarak anlamlı bir düşüşe neden olduğu görülmüştür. İzlem ölçüm sonuçlarnna göre düşen belirti düzeylerinin dört ay sonrasında da aynı aralıkta devam ettiği izlenmiştir. Kontrol grubu için yapılan analize göre, kontrol grubunun ön test, son test ve izlem testi puanları arasinda anlamlı bir farklllık görülmemiştir. Bu sonuçlara göre; bilinçli farkındalık temelli bilişsel terapi programının, obsesif kompulsif bozukluğun tedavisinde destekleyici bir müdahale olarak değerlendirilebilir olduğ $u$ düşünülmektedir.

Anahtar Kelimeler: Bilinçli farkındalık temelli bilişsel terapi, bilişsel terapi, obsesif kompulsif belirtiler, obsesif kompulsif bozukluk 


\title{
The Effect of Mindfulness Based Cognitive Therapy Program on Reducing Obsessive Compulsive Symptoms
}

\begin{abstract}
In the treatment of obsessive compulsive disorder, which shows an increasing prevalence steadily, cognitive behavioral therapy, especially mindfulness based approaches described as the third wave of cognitive therapies, have been shown to be effective in the literature. The aim of this study was to examine the effects of mindfulness based cognitive therapy on obsessive compulsive symptoms. An experimental study with experiment and control groups, pre-test and post test, and follow up model was designed. The data were collected with "Personal Information Questionnaire" for the personal information, "SLC-90 Symptom Checklist" to examine the inclusion criteria of participants, and "Padua Inventory" to determine the level of obsessive compulsive symptoms. The results showed that the intervention program implemented to the experimental group caused a statistically significant decrease in the obsessive compulsive symptoms of the participants. Follow up test scores showed that experimental group maintained the decreased level of symptoms throughout four months. No significant differences were found between pre and post-test and follow up scores of the control group. According to the results, mindfulness based cognitive therapy could be used as a supportive intervention for the treatment of obsessive compulsive disorder.
\end{abstract}

Keywords: Mindfulness based on cognitive therapy, cognitive therapy, obsessive compulsive symptoms, obsessive compulsive disorder 


\section{Giriş}

Obsesyon kelimesinin kökeni Latince "obsidere" kelimesine dayanmakta ve tedirgin eden, bireye rahat vermeyen, bunaltan anlamlarını taşımaktadır. Psikiyatri literatüründe ise bireyin yanlış olduğunu bilmesine karşın zihninden çıkaramadığı, muhakemesi ile anlamlandıramadığı ve arzu etmediği takıntılı düşünceler olarak tanımlanmıştır (Sakallı, 2014).

DSM-5'de obsesif kompulsif bozukluk tanımlanırken, temel iki başlı̆ga yer verilmiştir; takıntı (obsesyon) ve zorlantı (kompulsiyon). Obsesyonlar, bireyin zorla ve arzulamadan yaşadığı, genellikle belirgin kaygı sebebi olan tekrarlayıcı düşünceler, itkiler veya imgeler olarak tanımlanmıştır. Birey bu düşüncelere, itki veya imgelere aldırış etmemeye çalışırken, başka bir eylem ile bu düşünceleri yüksüzleştirmeye çalışabilir. Kompulsiyonlar, obsesyonlara tepki olarak, bireyin yapmak zorunda hissettiği davranışlar olarak tanımlanmıştır. En yaygın kompulsiyonlara örnek olarak, el yıkama, düzen ve denetleme davranışları ile sayı sayma, sessizce sözcükleri tekrarlama gibi zihinsel eylemler verilebilir. Bu kompulsiyonların amacı bireyi yaşadığı kaygı ya da sıkıntıdan uzaklaştırmaktır. Ancak bu kompulsiyonlar ile deneyimlenen kaygı arasında, gerçek anlamda kaygıyı azaltacak bir ilişki bulmak oldukça güçtür. Kompulsiyonlar bireyin zamanını aldığı gibi, klinik açıdan da belirgin bir sıkıntıya, toplumsal ve iş ile ilgili alanlarda işlev düşmesine sebep olabilmektedir (APA, 2013).

Sorumluluk algısının ortaya çıkardığı kaygının azaltılması için kaçma, kaçınma ve/veya tekrarlama stratejileri kullanılmaktadır. Bu stratejiler bireyin yaşam alanını daralttı̆̆ı gibi işlevselliğini de olumsuz yönde etkileyebilmektedir. Bu nedenle kaygiya neden olan obsesif düşünceler bireyin zihnine geldiğinde tepki verme dürtüsü oluşmaktadır. Bu dürtü ise kompulsiyonlar ile sonuçlanmaktadır. Bu döngünün kırılabilmesi zamanla daha zor bir durum alabilmektedir. Bilişsel davranışçı yaklaşım, bu döngüyü kırabilmek için sistematik maruz bırakma ve tepki önleme gibi stratejiler ile birlikte gevşeme egzersizlerini kullanmaktadır (Şenormancı, Konkan, Güçlü ve Sungur, 2012). Literatürde obsesif kompulsif bozukluk tedavisinde bilişsel davranış̧̧ı psikoterapi yaklaşımını destekleyen çok sayıda yayın bulunmaktadır (Kozak ve Foa, 1997; Abramowitz, Franklin, Schwartz ve Furr 2003; Barret, Healy-Farrel ve March, 2004; Şafak, Karade- 
re, Özdel, Özcan, Türkçapar, Kuru ve Yücens, 2014; Whittal, Thordason ve McLean, 2005; Olatunji, Davis, Powers ve Smits, 2013).

\section{Bilişsel Farkındalık Temelli Bilişsel Terapi}

Obsesif kompulsif bozukluk, bilişsel ve davranışsal boyutları olan obsesyonlar ve kompulsiyonlardan oluşmaktadır (Sadock ve Sadock, 2008). Obsesif kompulsif bozukluğun açıklanmasında bilişsel modellere başvuran görüşler literatürde uzun zamandır yer edinmiş yaygın görüşlerdir (Clark, 2004). Bilişsel davranış̧̧ı kuram, obsesif kompulsif bozuklukta görülen obsesyonların, inatçı düşüncelerden farklı olmadığını belirterek, bu obsesyonların inatçı düşünceler ile başlamakta olduğunu ifade etmektedir. Kurama göre obsesif düşüncelerin klinik obsesyonlardan farkı bulunmamaktadır. Yaygın görüşün aksine, toplumun büyük kısmında bulunmaktadırlar. Bilişsel davranışçı kuram, klinik olarak görülen obsesyonları inatçı düşüncelerden ayıran temel farkın, klinik görülen obsesyonların bireyi oluşabilecek zararlardan koruduğuna inanılması veya zararın önlenmesinde bireyin kendini sorumlu olarak görmesi ve yorumlaması olduğunu ifade etmektedir (Salkovskis, 1985). Kurama göre, bireylerin önemli bir kısmında zorlayıcı düşünceler ve/veya dürtüler bulunabilmekte, bu zihinsel süreci birey kendi sorumluluğu ile açıklama eğilimi gösterdiğinde ise tablo klinikleşmektedir.

Bilişsel davranışçı terapi yaklaşımı, yakın zamanlı literatür çalışmalarında bilinçli farkındalık müdahalelerine de yer vermekte ve ortak kullanımına ilişkin müdahale uygulamaları geliştirmektedir (Segal, Williams ve Teasdale, 2018; Lucas, Klepin, Porges ve Rejeski, 2018; Wielgosz ve ark., 2018; Kabat-Zinn, 2009). Bilinçli farkındalık yaklaşımının içeriğine ve psikoterapi alanında kullanımına ilginin artması, bilinçli farkındalık temelli bilişsel terapinin deneysel kullanımına ve araştırılmasına yol açmıştır.

Bilinçli farkındalık tanımı üç farklı anlamı içinde barındırmaktadır. Bir kuramsal temeli ifade ettiği gibi farkındalığın artması için yapılan pratikler anlamında da kullanılmaktadır. Ayrı olarak, zihinsel ve ruhsal bir süreç olarak tanımlanan "bilinçli farkında olma" durumunu da ifade etmektedir (Germer, Siegel ve Fulton, 2016). Bilinçli farkında olma durumu uygulanan meditasyon pratikleri ile geliştirilebilen zihinsel ve ruhsal bir süreçtir (Bishop ve ark., 2004). Geçmişte deneyimlenmiş veya gelecek için 
planlanmış olası deneyimlerde ve duygularda takılı kalmadan, sadece şimdiki an'ı deneyimleyebilmek, şimdiki an'ı kabul edebilmek şeklinde tanımlanmaktadır. Bilinçli farkındalık deneyimi, şimdiki an'a ilişkin bilişleri ve içinde bulunulan mekanı benimseyip kabul etmeyi barınd1ran fiziki farkındalığı içermektedir (Bishop ve ark., 2004; Kabat-Zinn, 2009).

Bilinçli farkındalık temelli bilişsel terapi yaklaşımının etkililiğini sınayan bilimsel çalışmaların yaklaşık olarak 30 yıllık bir literatür geçmişi bulunmaktadır. Ancak obsesif kompulsif bozukluk üzerindeki etkisini sınayan ilk çalışma Hertenstein ve ark. (2012) tarafından yapılmıştır. Çalışmada 12 katılımcı ile oluşturulan müdahale grubuns sekiz haftalık bir terapi uygulanmıştır. Uygulamada sistematik maruz birakma ve tepki önleme stratejileri ile birlikte bilinçli farkındalık yaklaşımı entegre edilerek çalışılmıştır. Hertenstein ve ark. (2012), obsesif kompulsif bozukluk için bilinçli farkındalık temelli bilişsel terapi tekniklerinin kabul edilebilir ve etkili olduğunu ifade etmiştir. Sekiz hafta süresince ve sonrasında katılımcların betimledikleri belirti düzeylerinde azalma, şimdiki zamanda daha etkin bir biçimde kalabilme, hoş görülmeyen duygulara gösterilen toleransin artması, hem günlük hayatta hem obsesif kompulsif bozukluk belirtilerinde daha hoşgörülü bir anlayış ve tutum ile birlikte duygulanım ve uyku kalitesinin arttı̆̆ yönünde geribildirimler verilmiştir. Elde edilen sübjektif geribildirimlere göre, gerçekleştirilen uygulama obsesif kompulsif belirtiler üzerinde etkili olmuştur.

Külz ve ark. (2014) tarafından gerçekleştirilen diğer bir çalışma protokol olarak sunulmuştur. Psikiyatri desteği ve/veya bilişsel davranışçı psikoterapi desteği almış ancak tam iyileşme görülmemiş bireyleri kapsayan çalışma, kontrol gruplu ve yapılandırılmış bir pilot çalışma olarak sunulmuştur. Oluşturulan bir grup bilinçli farkındalık temelli bilişsel terapi programına, diğer grup ise psikoeğitim koçluğu programına dahil edilmiştir. Çalışmanın sonucunda bilinçli farkındalık temelli bilişsel terapi programına katılan bireylerin obsesif kompulsif belirti düzeylerinde anlamlı derecede düşme görüldüğü belirtilmiştir.

Bilinçli farkındalık temelli bilişsel terapi yaklaşımının obsesif kompulsif belirtilerin sağaltımında faydalı olduğuna ilişkin literatürde destekleyici yayınlar bulunmaktadır. Ancak bilinçli farkındalık pratikleri- 
nin psikoterapi alanında kullanılması çok yakın tarihe dayanmaktadır. Bu nedenle çalışma sayısı oldukça sınırlıdır. Bu çalışmada, bilinçli farkındalık temelli bilişsel terapi programının, bireylerin obsesif kompulsif belirti düzeyleri üzerindeki etkisi incelenmesi amaçlanmıştır.

\section{Yöntem}

Bu çalışma deneysel bir çalışma olarak tasarlanmıştır. Araştırma desenini (2x3) müdahale ve kontrol grubu için ön test, son test ve izlem testi ölçümleri oluşturmaktadır.

\section{Örneklem}

Çalışma grubu, herhangi bir kısıtlama olmaksızın İstanbul ilinde ikamet eden bireylerden, örneklem ise çalışma grubundaki bireylerden Padua Envanteri'nde en yüksek ölçek puanına sahip olan ve aynı zamanda araştırma için gereken kriterleri (tanı almamış olması, psikiyatrik ilaç kullanıyor olmaması vb.) sağlayan 11'i kadın ve 11'i erkek olmak üzere 22 kişilik gruptan oluşmaktadır. Katılımcıların yaş aralığı 19-36 olup, yaş ortalaması

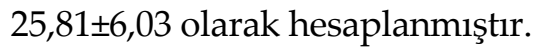

\section{Veri Toplama Araçları}

Katılımcıların yaş, cinsiyet, eğitim, maddi durum gibi demografik bilgilerini incelemek amacıyla araştırmacı tarafından hazırlanmıştır. Bununla birlikte form; ilaç kullanım geçmişi, psikiyatri öyküsü ve son altı ayda psikiyatri tedavisi ve/veya psikoterapi geçmişine ilişkin soruları da içermektedir.

Padua Envanteri Revize Edilmiş Formu:Padua Envanteri Revize Edilmiş Formu, obsesif kompulsif bozukluğun yaygın görülen alt tiplerini ölçmek amaciyla Sanavio (1988) tarafından geliştirilmiş ve Oppen, Hoekstra ve Emmelkamp (1995) tarafından revize edilmiştir. Orijinal envanterde 60 madde, revize edilmiş formunda ise 41 madde bulunmaktadır ve revize form sadece klinik olmayan grubu belirlemek için değil, obsesif kompulsif bozukluk belirtilerini inceleyebilmek ve ölçebilmek için de geçerli bir öl- 
çüm aracı olarak belirtilmektedir. Envanterin hem orijinal formunun hem de revize edilmiş formunun Türkçe uyarlaması Beşiroğlu ve ark. (2005) tarafından yapılmıştır. Envanter, temizlik, dürtüler, kontrol, düşüncelere kapılma ve kesinlik olmak üzere beş faktörden oluşmaktadır. Ölçeğin Cronbach alfa değeri 0,95 ve test tekrar test güvenirliğini 0,91 olarak belirtmiştir.

SCL-90 Belirti Tarama Listesi:Test, Derogatis ve Cleary (1977) tarafından psikiyatrik belirtiler gösteren bireyleri ayırt edebilmek amacıyla geliştirilmiştir. Ölçeğin Türkçe uyarlaması Dağ (1991) tarafından yapmıştır. Toplamda 90 maddeden oluşmakta ve beşli likert ölçek olarak derecelendirilmektedir. Somatizasyon, obsesif kompulsif bozukluk, kişiler arası duyarlılik, depresyon, anksiyete, öfke, fobi, paranoid düşünce ve psikotik belirtiler olmak üzere toplamda dokuz alt alanı derecelendirmektedir. Dokuz alt alandan elde edilen puanlarının ortalaması ise genel semptom ortalamasını vermektedir.

\section{Uygulama}

Uygulama araştırmacı tarafından İstanbul ilinde gerçekleştirilmiştir. Müdahale ve kontrol grup katılımcıları, çalışma grubu olarak belirlenen 577 kişilik bir havuzdan seçilmiştir. Padua Envanteri'nden en yüksek puanı alan 50 kişi ile ön görüşme yapılmıştır. Ön görüşmede programın şeması, katılımcılardan beklenenler, katılımcı kriterleri, devam ve gönüllülük esası hakkında bilgilendirme yapılmış ve Belirti Tarama Listesi (SCL-90R) uygulanmıştır. Müdahale ve kontrol grupları için belirlenen kriterler; devam eden bir psikiyatri tedavisi veya psikoterapi sürecinde olunmamasi, son altı ay içerisinde alkol veya madde alınmamış olması, son altı ay içerisinde psikiyatri tedavisi görmemiş ve buna bağlı herhangi bir ilaç kullanmamış olması, hayat boyu süren ve çalışmaya katılmasını engelleyebilecek nörolojik bir bozukluğun olmaması, intihara meyilli belirtilere rastlanılmaması ve kişilik bozukluğu tanısı bulunmaması olarak belirlenmiştir. Bunlarla birlikte, bilgilendirilmiş onamda da belirtildiği gibi iki oturumdan fazla devamsızlık gösteren katılımcılar çalışmaya dahil edilmemiştir.

Hazırlanan Bilinçli Farkındalık Temelli Bilişsel Terapi Programı 06 Aralık 2018 - 24 Ocak 2019 tarihleri arasında toplamda sekiz hafta olarak ger- 
çekleştirilmiştir. Müdahale grubu ile haftada bir kez 150 dakikalık Bilinçli Farkındalık Temelli Bilişsel Terapi Programı oturumları gerçekleştirilmiştir. Kontrol grubu ile bu süre zarfında uygulama yapılmamıştır. Oturumlar başlamadan önce müdahale ve kontrol gruplarından ön test ölçümleri alınmıştır. Müdahale grubunun oturumları tamamlandığı hafta, her iki gruba da Padua Envanteri son test olarak uygulanmıştır. Çalışmanın tamamlanmasından yaklaşık dört ay sonra ise izlem ölçümü alınmıştır. Müdahale grubunun her oturumunda bilişsel davranışçı pratikler ağırlıklı tutulmuştur. Oturumların \%75'lik kısmının bilişsel davranışçı uygulamaları içermesine, diğer \%25'lik kısmının ise farkındalık temelli çalışmalara ayrılmasına özen gösterilmiştir.

\section{Bilinçli Farkındalık Temelli Bilişsel Terapi Programının Oluşturulması:}

Müdahale grubu programı, araştırmacı tarafından birçok kaynaktan faydalanılarak düzenlenmiştir (Williams ve Penman, 2015; Türkçapar, 2009; Şafak ve ark., 2014; Atalay, 2018; Segal ,Williams ve Teasdale, 2018).

Bilişsel davranışçı terapi, farkındalık temelli bilişsel terapi ve farkındalık temelli stres azaltma uygulamaları temel zemin olarak alınmıştır. Programın içeriği hazırlanırken kuramsal temellere dikkat edilmiştir. Her oturumun amacı, uygulamaları, çerçevesi ve gerekli görülen ödevleri içeren dokümanlar program başlamadan önce hazırlanmıştır.

\section{Hazırlanan Programın Oturum Özetleri}

Oturumlar literatür dikkate alınarak haftada bir 150'şer dakika olacak şekilde düzenlenmiş, tüm oturumlarda paylaşımlar daire düzeninde oturularak gerçekleştirilmiştir. Bu bölümde oturumlarda genel olan yapılanlar belirtilecektir.

Birinci Oturum: Grup üyelerinin karşılanmasının ardından daire biçiminde yerleşim sağlandı. Grup üyeleri ile birlikte uyulması gereken kurallar belirlendi. Grup üyelerinden oturdukları yerde en rahat nasıl iseler öyle oturmaları istendi. Ardından kuru üzüm meditasyonu uygulandı. Her grup üyesine kuru üzüm verildi ve yaklaşık olarak on dakika boyunca kuru üzüme odaklanmaları istendi. Bu süre zarfında dikkatlerini toplamakta zorlanmamaları için kuru üzüme ilişkin, "dokusu nasıl, sıcak mı 
yoksa soğuk mu, yüzeyi nasıl, pürüzlü mü yumuşak mı" gibi sorular iletilerek, devamında dokusuna, sıcaklığına, pürüzlerine ve çekirdeklerine odaklanmaları yönünde telkinler verildi. Grup üyelerinin geri bildirimleri alındıktan sonra süreç hakkında bilgi verildi. Terapi stratejileri özet olarak aktarıldı. Gizlilik ilkesi tekrar hatırlatıldı ve geri bildirimlerin dinlenilmesi ile oturum sonlandirıldı.

Íkinci Oturum: Olumsuz düşüncelere hapsolmak yerine an'da olmayı seçme ve nefes alarak bedenin bilincinde olmabilme alışkanlığ 1 hakkında bilgi verildi. Farkındalık ile nefes almayı öğrenmenin, an'da kalmayı sağlayan en iyi yollardan biri olduğu uygulamalar ardından ifade edildi. Nefes egzersizine başlamadan önce katılımcıların rahat bir şekilde oturmaları sağlandı. Nefeslerini, bir duygu ve düşüncelerini yüzeye çıkaran bir çapa gibi kullanmaları yönünde yönergeler verildi. Egzersiz bittikten sonra, grup üyelerine dikkatlerini nefeslerine odakladıkları zaman zihinlerini meşgul eden düşünceleri soruldu. Katılımcıların birçoğu nefes egzersizi esnasında, onları etkileyen düşüncelerin yavaşça uzaklaştığı veya yok olduğu yönünde geri bildirim verdiler.

Üçüncü Oturum: Bir önceki oturumdan bu oturuma kadar geçen sürede yapılan egzersizler dinlenildi. Katılımcılar egzersizleri uygularken yaşadıkları dirençleri ve uyguladıktan sonraki deneyimlerini ifade ettiler. Düzenli olarak nefes egzersizi yapan katılımcılar düşünceyi an'a odaklarken olumsuz düşüncelerinden sıyrılabildiklerini belirttiler. Ardından bir önceki haftanın özeti yapılarak bilişsel davranışçı kısma geçildi. Grup üyelerine rasyonel, açıklaması olmayan ancak inandıkları düşünceleri olup olmadığı sorularak, grup üyeleri dinlendi ve bu inançları takip etme ödevi verildi.

Dördüncü Oturum: Gruba bir önceki oturumdan bu oturuma kadar geçen süre zarfında uyguladıkları farkındalık egzersizleri hakkında konuşularak başlandı. Grup üyelerinden biri, baş edemediği düşüncelerle artık daha iyi mücadele ettiğini ve zihninde aynı anda birden fazla çarpıtma yakaladığ1$\mathrm{n}$, nefese odaklandığında bu olumsuz düşüncelerin önemli oranda azaldığını ve "uzaklaştı̆̆ını" ifade etti. Obsesyon (takıntı) ve kompulsiyon (zorlantı) terimleri açıklandı. Grup üyeleri farkına vardıkları obsesyonları 
hakkında konuştu. Bu "sıkıntılı düşüncelerden" kurtulmak amacıyla yaptıkları davranışlar olup olmadığı soruldu. Paylaşımlar tamamlandıktan sonra beden taraması ve özşefkat medi- tasyonu uygulandı. Grup üyelerinden biri özşefkat uygulamasında kendine dönük olarak ilk kez merhamet hissettiğini paylaştı. Grup üyelerine bir sonraki oturuma kadar her iki egzersizi düzenli yapabilmeleri için doküman verilerek oturum kapatıldı.

Beşinci Oturum:Bir önceki oturumdan bu oturuma kadar yapılan egzersizler dinlenilerek oturuma başlandı. Ardından bir önceki oturumun özeti yapıldı ve zihinlerini sürekli meşgul eden istemsiz düşünceler hakkında konuşuldu. Grup üyelerinden biri düşünceleri ile daha kolay baş edebildiğini ve düşüncelerini organize edebilmeye başladığını ifade etti. Bilişsel çarpitmalar, otomatik düşünceler ve obsesyonlar tekrar özetlendi ve bunlar ile baş etme stratejileri üzerine tartışıldı. Olumsuz baş etme stratejilerinin yeniden yapilandırılmasına yardımc olundu. Obsesyonlar ve kompulsiyonlar arasındaki ilişki örneklendirilerek grup üyelerinin paylaşımları dinlendi. Nefese, şimdi ve burada kalabilmeye yönelik egzersizler uygulatıldı. Bireysel olarak yaşanan bilişsel çarpıtmaların kayıtlarının tutulması istenilerek oturum kapatıldı.

Altıncı Oturum:Gruba başlarken bir önceki oturumdan bu oturuma değin yapılan farkındalık egzersizleri ve bireysel olarak yaşadıkları bilişsel çarpıtma kayıtlarını paylaşan üyeler dinlendi. Grup üyelerinin bilişsel çarpıtmaları dinlenirken, bilişsel çarpıtmalarından ara inançlarına ve ara inançlarından şemalarına ulaşabilmelerine yönelik sorgulamalar yapıldı. Maruz bırakma ve yanıt önleme açıklandı. Grup üyelerinden maruz bırakma ve yanıt önleme pratiğine dahil olmaları istenildi. Oluşturdukları kayg1 seviyesine göre imajinasyon tekniği kullanılarak maruz bırakma deneyimlendi. Bir sonraki oturuma kadar oturum dişında da maruz b1rakma deneyimi ödevi verildi. Farkındalık egzersizi uygulanarak oturum kapatildı.

Yedinci Oturum:Oturuma, grup üyelerinin bir önceki oturumdan sonra yaşadıkları egzersiz deneyimleri ve maruz bırakma ödevleri hakkında konuşularak başlandı. Devamında tekrar maruz bırakma pratiği uyguland. Objeye tepki olarak kompulsif davranışları engellendiğinde ortaya 
çıkan kaygı konuşuldu. Ardından tek bir şey düşünmeye odaklanan farkındalık çalışması uygulandı. Uygulama bittiğinde grup üyelerinin çoğunluğu obsesif düşüncelerden uzaklaşabildiklerini sözel olarak ifade etti. Düşünceleri kabul edebilmeye yönelik nefes egzersizi uygulandı. Her iki farkındalık egzersizinin bir sonraki buluşmaya kadar uygulanması istenilerek oturum kapatıld.

Sekizinci Oturum:Bir önceki oturumdan sonra deneyimledikleri egzersizler üzerinde durularak oturuma başlanıldı. Bu oturumun programın son oturumu olması sebebiyle sürecin tamamı özetlendi, grup üyelerinin geri bildirimleri ve soruları dinlendi. Grup üyelerinin çoğunluğu takıntılı düşünceleriyle daha iyi baş ettiklerini ve bu düşünceleri ile baş etmekte kullandıkları davranışlarının önemli ölçüde değiştiğini ifade ettiler. Obsesif kompulsif belirtilerin yeniden artmasına yol açabilecek durumların örneklendirilmesi grup üyelerinden dinlendi. Bunu engellemek adına stratejiler paylaşıldı. Kısa süreli (üç dakikalık) bir nefes egzersizi uygulatıldı. Ardından son test uygulamaları yapıldı ve veda edildi.

\section{Verilerin Analizi}

Uygulamada elde edilen veriler SPSS 20.0 versiyonu ile analiz edilmiştir. Çalışmada ilk olarak katılımcların demografik özellikleri, frekans dağılımları ve ölçümlerden elde edilen puanların betimleyici istatistiklerine yer verilmiştir. Müdahale ve kontrol gruplarının cinsiyet dağılımlarının homojen olup olmadığı Ki-Kare Analizi ile müdahale ve kontrol gruplarının ön test puan ortalamalarının ve yaşlarının arasında farklılaşma olup olmadığ 1 Bağımsız Örnek t Testi ile incelenmiştir. Bilinçli farkındalık temelli bilişsel terapi programının obsesif kompulsif belirtiler üzerindeki etkisini inceleyebilmek için, Tekrarlı Ölçümler İçin İki Yönlü Varyans Analizi uygulanmıştır. Bu analiz için gerekli olan varsayımlar; ölçümlerden elde edilen puanlar ile ölçümler arası fark puanlarının dağılımlarının normal dağılım olması ve küresellik varsayımı (sphericity) olarak sıralanabilir (Güriş, Astar, 2019). Normal dağılım varsayımı için Shapiro-Wilk testi, fark serilerinin varyanslarının homojenliğinin incelenmesi için ise Mauchly's Küresellik Testi kullanılmıştır. 


\section{Bulgular}

Müdahale ve kontrol gruplarını oluşturmak için seçilen çalışma grubu, 326 's kadın $(\% 65,5)$ ve 251 'i erkek $(\% 43,5)$ olmak üzere 577 kişiden oluşmaktadır. Müdahale ve kontrol gruplarının oluşturulabilmesi için seçilen bu grubunun Padua Envanteri puanları büyükten küçüğe doğru sıralanmış, en yüksek puanlara sahip katılımcılar ile birebir görüşme yapılmış, çalışmaya katılmayı kabul eden bireyler müdahale ve kontrol gruplarına rastgele atanmıştır. 22 kişiden oluşan ve kadın ile erkek birey sayısı eşit olan örneklemde, Padua Envanteri puan ortalaması 84,82 $\pm 12,50$ olarak hesaplanmıştır. Aynı ortalama çalışma grubunda ( $n=577)$ ise $39,87 \pm 21,54$ olarak elde edilmiştir. Örneklemin gruplar açısından tanımlayıcı istatistiklerinin detayları sunulmuştur (Tablo 1).

Tablo 1. Örneklemin Gruplar Açısından Tanımlayıcı İstatistik Değerleri

\begin{tabular}{lllllcc}
\hline Değişken & & n & Min. & Maks. & $\overline{\mathbf{X}}$ & ss. \\
\hline \multirow{5}{*}{ Kontrol } & Ön Test Puanı & 11 & 67,00 & 109,00 & 83,36 & 12,81 \\
& Son Test Puanı & 11 & 69,00 & 111,00 & 85,18 & 12,62 \\
& İzlem Testi Puanı & 11 & 71,00 & 110,00 & 84,27 & 11,82 \\
& Yaş & 11 & 19,00 & 31,00 & 24,27 & 4,31 \\
\hline \multirow{5}{*}{ Müdahale } & Ön Test Puanı & 11 & 68,00 & 103,00 & 86,27 & 12,63 \\
& Son Test Puanı & 11 & 33,00 & 71,00 & 50,45 & 11,23 \\
& İzlem Testi Puanı & 11 & 30,00 & 67,00 & 49,73 & 11,11 \\
& Yaş & 11 & 19,00 & 36,00 & 25,82 & 6,03 \\
\hline
\end{tabular}

Kontrol ve müdahale grupları ayrı olarak değerlendirildiğinde; kontrol grubunun ön test ölçümlerinden elde edilen en düşük puan 67, en yüksek puan 109 ve ortalaması 83,36 $\pm 12,81$ olarak hesaplanmıştır. Kontrol grubu son test ölçümlerinden elde edilen en düşük puan 69, en yüksek puan 111 ve ortalaması $85,18 \pm 12,62$ 'dir. Kontrol grubu izlem testi ölçümlerinden ise elde edilen en düşük puan 71,00 , en yüksek puan 110 ve ortalama $84,27 \pm 11,82$ ' dir. Kontrol grubunda yer alan en düşük yaş değeri 19 iken en yüksek yaş değeri 31 'dir. Kontrol grubu yaş ortalaması $24,27 \pm 4,31$ 'dir.

Müdahale grubunun ön test ölçümlerinden elde edilen en düşük puan 68, en yüksek puan 103 ve ortalama 86,27 $\pm 12,63$ olarak elde edilmiştir. Müdahale grubunun son test ölçümlerinden elde edilen en düşük puan 33, en

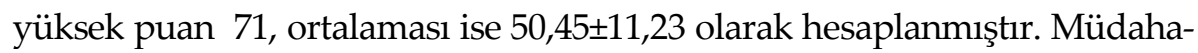
le grubu için yapılan izlem ölçümünde elde edilen en düşük puan 30, en 
yüksek puan 67 ve ortalaması 49,73 $\pm 11,11$ olarak elde edilmiştir. Müdahale grubunda yer alan en düşük yaş değeri 19, en yüksek yaş değeri ise 36 'dır ve yaş ortalaması $25,82 \pm 6,03$ olarak elde edilmiştir.

Katılımcıların puan ve yaş ortalamalarının gruplar açısından farklıl1k gösterip göstermediği incelemiştir (Tablo 2).

Tablo 2. Ön Test Puanlarıın Kontrol ve Yaş Değerlerinin Müdahale Gruplarına Göre Bă̆ımsız Örnek $t$ Testi ile Karşılaştırılması

\begin{tabular}{llcccccc}
\hline Değişken & Grup & $\mathbf{n}$ & $\overline{\mathrm{X}}$ & $\mathbf{s s .}$ & $\mathbf{t}$ & $\mathbf{s d}$ & $\mathbf{p}$ \\
\hline \multirow{2}{*}{ Ön Test Puanı } & Kontrol & 11 & 83,36 & 12,81 & \multirow{2}{*}{0,54} & \multirow{2}{*}{20} & \multirow{2}{*}{0,60} \\
& Müdahale & 11 & 86,27 & 12,63 & & & \\
Yaş & Kontrol & 11 & 24,27 & 4,31 & $-0,69$ & \multirow{2}{*}{20} & 0,32 \\
\hline
\end{tabular}

Kontrol ve müdahale gruplarından elde edilen ön test puanlarının gruplara göre farklılaşıp farklılaşmadığını sınamak için yapılan Bağımsız Örnek $t$ Testi sonucuna göre kontrol grubunun ön test puan ortalaması $(\bar{x}=83,36)$ ile müdahale grubunun ön test puan ortalaması $(\bar{x}=86,27)$ arasinda istatistiksel olarak anlamlı bir farklılık gözlenmemiştir, $\mathrm{t}(20)=-0,54$; $p>0,05$. Kontrol ve müdahale gruplarının yaş değişkenine göre de tekrarlanan test sonucu, kontrol grubunun yaş ortalaması $(\bar{x}=24,27)$ ile müdahale grubunun yaş ortalaması $(\bar{x}=25,82)$ arasında istatistiksel olarak anlamlı bir farklılık gözlenmemiştir, $t_{(20)}=0,69 ; p>0,05$. Bilinçli Farkındalık Temelli Bilişsel Terapi Programına dahil edilen bireylerin ön test puan ortalaması ve yaş ortalaması ile uygulamaya tabii tutulmayan kontrol grubu ön test puan ortalaması ile yaş ortalaması arasında istatistiksel olarak anlamlı fark olmaması, uygulanacak terapi programının etkinliğinde yaş faktörünün etkili olmayacağı ve psikoterapinin etkinliğinin güvenli bir biçimde incelenebileceği açısından önemli bir ölçüttür.

Müdahale grubunda yer alan katılımcıların cinsiyet dağılımı açısından homojen olup olmadığı Tek Örnek Ki-Kare Analizi ile incelenmiştir (Tablo 3).

Tablo 3. Müdahale Grubu Cinsiyet Dağılımının Tek Örnek Ki-Kare Analiz Sonuçları

\begin{tabular}{lccccc}
\hline Cinsiyet & Gözlenen Frekans & Beklenen Frekans & $\chi^{2}$ & sd & p \\
\hline Kadın & 5 & 5,5 & 0,091 & \multirow{2}{*}{1} & 0,76 \\
Erkek & 6 & 5,5 & & & \\
\hline
\end{tabular}


Yapılan analiz sonucuna göre müdahale grubunun kadın ve erkek oranları arasında istatistiksel olarak anlamlı bir farklılık bulunmamaktatadır, $\chi_{1}^{2}=0,091 ; p>0,05$. Bu sonuca göre müdahale grubunda cinsiyet dağ1lımının homojen olduğu ve cinsiyet dağılımının uygulanacak terapi programının etkinliğinde farklılığa neden olmayacağı söylenebilir.

Terapi programının etkinliği için uygulanacak analiz için ilk varsayım olan ön test, son test ve izlem testi ölçümlerinden elde edilen puanları arasındaki farkların normal dağılım varsayımını sağlayıp sağlamadığının incelenmesi için katılımcı sayısının 30'un altında olması nedeniyle normallik Shapiro-Wilk istatistiği tercih edilmiş ve sonuçları verilmiştir (Tablo 4).

Tablo 4. Katılımcıların Ön Test, Son Test, İzlem Testi Ölçümleri Arası Fark Serilerinin Normallik Analizi Sonuçları

\begin{tabular}{llccc}
\hline \multirow{2}{*}{ Grup } & Fark Serileri & $\begin{array}{c}\text { Shapiro } \\
\text { Wilk }\end{array}$ & sd & p \\
\hline \multirow{4}{*}{ Kontrol } & Ön test ve Son Test Farkı & 0,97 & 11 & 0,49 \\
& Ön Test ve İzlem Testi Farkı & 0,90 & 11 & 0,13 \\
& Son Test ve İzlem Testi Farkı & 0,92 & 11 & 0,18 \\
\hline \multirow{3}{*}{ Müdahale } & Ön test ve Son Test Farkı & 0,93 & 11 & 0,23 \\
& Ön Test ve İzlem Testi Farkı & 0,96 & 11 & 0,79 \\
& Son Test ve İzlem Testi Fark1 & 0,84 & 11 & 0,97 \\
\hline
\end{tabular}

Analiz sonucuna göre; kontrol grubu ön test ve son test arasındaki fark serisi, ön test ve izlem testi arasındaki fark serisi ve son test ve izlem testi arasındaki fark serisi (SWös $=0,97 ; \mathrm{p}>0,05, \quad S W_{\text {öi }}=0,90 ; \mathrm{p}>0,05$, $\left.\mathrm{SW}_{\mathrm{si}}=0,92 ; \mathrm{p}>0,05\right)$ ile müdahale grubu ön test ve son testi arasındaki fark serisi, ön test ve izlem testi arasindaki fark serisi, son test ve izlem testi arasındaki fark serisi ( $S W_{o ̈ s}=0,93 ; p>0,05, S W_{o ̈ i}=0,96 ; p>0,05, S W_{s i}=0,84$; $\mathrm{p}>0,05)$ normal dağılım göstermektedir. Uygulanacak analizin diğer bir varsayımı olan küresellik varsayımı; ölçümler arası farkların varyanslarının homojenliğini gerektirmektedir. Bu varsayım Mauchly's Küresellik Testi ile incelenmiştir (Tablo 5).

Tablo 5.Mauchly's Küresellik Varsayımının Sınanması

\begin{tabular}{cccccc}
\hline \multirow{2}{*}{ Mauchly's W } & \multirow{2}{*}{ sd } & $\mathbf{p}$ & \multicolumn{4}{c}{ Epsilon } \\
\cline { 4 - 6 } & & & Greenhouse-Geisser & Huynh-Feldt & LowerBound \\
\hline 0,293 & 2 & 0,00 & 0,586 & 0,631 & 0,500 \\
\hline
\end{tabular}


Mauchly's Küresellik Testi sonucuna göre ölçümler arası farkların varyansları homojen değildir; $W=0,293 ; p<0,05$. Bu nedenle epsilon değerlerine göre düzeltme yapılması yoluna gidilmiştir. Epsilon değerleri 0,70'ten düşük olduğundan, Greenhouse-Geisser Düzeltmesi tercih edilmiştir. Obsesif kompulsif belirtiler deneyimleyen bireylerin belirti düzeylerini azaltmayı hedefleyen Bilinçli Farkındalık Temelli Bilişsel Terapi Programı'nın etkililiğini sınamak amacı ile Padua Envanteri ön test, son test ve izlem testi olarak müdahale ve kontrol grupları için tekrarlı alınan ölçüm puanlarının gruplar ve ölçümler arası farklılaşıp farklılaşmadığını sınamak için Greenhouse-Geisser düzeltmeli Tekrarlı Ölçümler İçin İki Yönlü Varyans Analizi test istatistiklerini içeren sonuçlar değerlendirilmiştir (Tablo 6).

Tablo 6. Ön Test, Son Test ve İzlem Testi Puanlar Arası Farklılı̆̆ın Tekrarlı Ölçümler İçin İki Yönlü Varyans Analizi ile İncelenmesi

\begin{tabular}{lcccccc}
\hline $\begin{array}{l}\text { Değişim } \\
\text { Kaynağı }\end{array}$ & $\begin{array}{c}\text { Kareler } \\
\text { Toplamı }\end{array}$ & sd & $\begin{array}{c}\text { Kareler } \\
\text { Ortalamas }\end{array}$ & $\mathbf{F}$ & $\mathbf{p}$ & $\boldsymbol{\eta}^{\mathbf{2}}$ \\
\hline $\begin{array}{l}\text { Gruplar Arası } \\
\text { Grup (M/K) }\end{array}$ & 2691,414 & 1 & 2691,414 & 21,883 & 0,00 & 0,522 \\
\hline Hata & 2459,818 & 20 & 122,991 & & & \\
\hline $\begin{array}{l}\text { Gruplar İçi } \\
\text { Ölçüm (Ön-Son-İzlem) }\end{array}$ & 4452,485 & 1,172 & 3800,275 & 66,455 & 0,000 & 0,769 \\
\hline Grup*Ölçüm & 5168,848 & 1,172 & 4411,704 & 77,147 & 0,000 & 0,794 \\
\hline Hata & 1340,00 & 23,432 & 57,186 & & & \\
\hline
\end{tabular}

M: Müdahale K: Kontrol

Katılımcların yer aldığı müdahale ve kontrol gruplarının ön test, son test ve izlem testi puan ortalamaları arasında fark olup olmadığının sınanması için yapılan analizden elde edilen sonuçlara göre istatistiksel olarak anlamlı bir farklılık gözlenmiştir, $\mathrm{F}_{(1-20)}=21,810 ; \mathrm{p}<0,001, \eta^{2}=0,522$. $\mathrm{Bu}$ sonuca göre müdahale ve kontrol grubunda yer alan katılımcıların Padua Envanteri puan ortalamaları, ölçüm ayrımı yapmaksızın (ön test, son test ve izlem testi) anlamlı derecede farklılaşmaktadır. Yapılan müdahale anlamlı farklılığa neden olmuştur. Bu farklılığın yaklaşık olarak \%52'si açıklanabilmektedir.

Bilinçli farkındalık temelli bilişsel terapi programına katılan müdahale grubu ve işlem yapılmayan kontrol grubunun grup ayrımı yapılmaksızın ön test, son test ve izlem testi puan ortalamaları arasında ista- 
tistiksel olarak anlamlı bir farklılık gözlenmiştir, $\mathrm{F}_{(1,172-23,432)}=66,455$; $\mathrm{p}<0,001, \eta^{2}=0,769$. Bu sonuca göre ölçümlerde grup ayrımı yapılmaksızın ölçüm puanları arasındaki farkın anlamlı olduğu ve puanların uygulanan terapi programına bağlı olarak farklılaştığı ifade edilebilir. Bu farklılığın yaklaşık olarak \%77'si açıklanabilmektedir.

Katılımciların yer aldığı müdahale ve kontrol grubu ile ön test, son test ve izlem testi ölçümlerinden elde edilen puanların ortak etkisi de istatistiksel olarak anlamlıdır, $\mathrm{F}_{(1,172-23,432)}=77,147 ; \mathrm{p}<0,001, \eta^{2}=0,794$. Bu sonuca göre; katılımcıların yer aldığı grubun ölçüm üzerindeki etkisi anlamlıdır ve yapılan deneysel işlemin katılımcıların Padua Envanteri puanlarında değişime neden olduğu söylenebilir. Diğer bir ifade ile katılımcların bulunduğu grup ile ölçümler arası farklılığın ortak etkisi anlamlı olduğundan, Padua Envanteri puanları deneysel işlemin bir sonucu olarak değişmektedir. Bu farklılığın \%79'u açıklanabilmektedir.

Tablo 7. Ön Test Son Test ve İzlem Testi Puanlarnnn Kontrol ve Müdahale Gruplarına Göre Bağı̆mlı Örnek $t$ Testi İle Karşılaştırılması

\begin{tabular}{llcccccc}
\hline \multirow{2}{*}{ Grup } & Değişken & $\mathbf{n}$ & $\begin{array}{c}\text { Fark } \\
\text { ort. }\end{array}$ & ss. & $\mathbf{t}$ & sd & p \\
\hline \multirow{3}{*}{ Müdahale } & Ön test- Son Test & 11 & 35,82 & 12,26 & 9,69 & 10 & 0,00 \\
& Ön test- İzlem Testi & 11 & 36,54 & 13,17 & 9,20 & 10 & 0,00 \\
& Son test- İzlem Testi & 11 & 0,73 & 3,04 & 0,79 & 10 & 0,44 \\
\hline \multirow{3}{*}{ Kontrol } & Ön test- Son Test & 11 & $-1,82$ & 5,46 & $-1,10$ & 10 & 0,29 \\
& Ön test- İzlem Testi & 11 & $-0,91$ & 5,15 & $-0,59$ & 10 & 0,57 \\
& Son test- İzlem Testi & 11 & $-0,91$ & 3,56 & 0,85 & 10 & 0,42 \\
\hline
\end{tabular}

Analiz sonucunda elde edilen farklılıkların hangi grup ve ölçümlerden kaynaklandığının incelenmesi için yapılan gruplar arası ve ölçümler arası karşılaştırma sonuçlarına göre, müdahale grubunun ön test puan ortalaması $(\bar{x}=86,27)$ ile son test puan ortalaması $(\bar{x}=50,45)$ arasinda istatistiksel olarak anlamlı bir farklılık gözlenmiştir; $p<0,01$. Uygulanan psikoterapi sonrası katılımciların obsesif kompulsif belirti düzeyleri puanlarında anlamlı bir düşüş gözlenmiştir. Ancak müdahale grubundaki katılımcıların psikoterapi sonrası son test puan ortalaması $(\bar{x}=50,45)$ ile izlem testi puan ortalaması $(\bar{x}=49,73)$ arasında istatistiksel olarak anlamlı bir farklılık gözlenmemiştir; $p>0,05$.

Herhangi bir uygulamaya alınmayan, sekiz hafta bekleme süresi verilen kontrol grubunun ön test $(\bar{x}=83,36)$ ve son test $(\bar{x}=85,18)$ uygulamas1 
puan ortalamaları arasında anlamlı bir farklılık görülmemiştir; $p>0,05$. Bu nedenle müdahale grubunun puan ortalamasında oluşan değişimin programdan kaynaklı olduğu ifade edilebilir. Bununla birlikte; müdahale grubuna işlem tamamlandıktan dört ay sonra uygulanan izlem ölçümü ile, program tamamlandığı esnada uygulanan son test ölçümünden elde edilen puan ortalamaları arasında da istatistiksel olarak anlamlı bir farklılık görülmemiştir; $p>0,05$. Bilinçli farkındalık temelli bilişsel terapi programının bireylerin obsesif kompulsif belirtilerine etkisi uzun süreli olarak devam etmiştir.

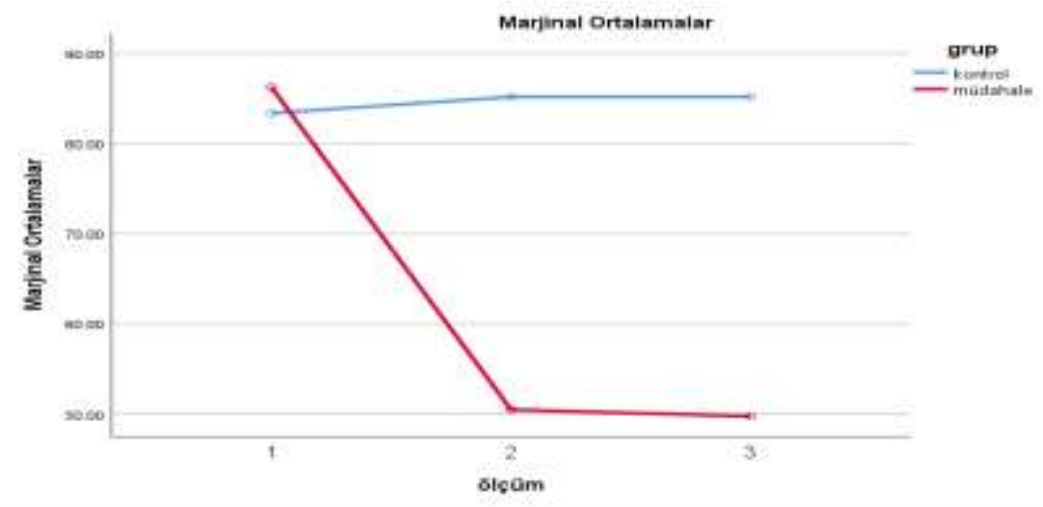

\section{Şekil 1. Kontrol ve Müdahale Gruplarının Ön Test, Son Test ve İzlem Testi Ortalamalarının Grafiği}

Kontrol ve müdahale gruplarının ön test, son test ve izlem testi ölçümleri Padua Envanteri puan ortalamaları grafikte gösterilmiştir (Şekil 1). Birinci ölçüm olan ön test ölçümünde koyu renk ile belirtilen müdahale grubu puan ortalaması ve açı renk ile belirtilen kontrol grubu ön test puan ortalaması birbirine oldukça yakınken; ikinci ölçüm olan son test puan ortalamalarının farklılaştı̆̆ gözlenmektedir. Kontrol grubu son test puan ortalaması hala oldukça yüksek iken müdahale grubu ortalamasının oldukça düştüğü söylenebilir. Aynı şekilde izlem testi puan ortalaması ele alındığında; kontrol grubu puan ortalaması, ön test ve son test puan ortalamasına benzer bir seyirde iken, müdahale grubunun izlem testi puan ortalaması, ön test puan ortalamasina göre oldukça düşük ve son test ortalamasına benzer bir seyirdedir. 
Tablo 8. Müdahale ve Kontrol Gruplarnın Padua Envanteri Aralıklarna Göre Stralanması

\begin{tabular}{llcc}
\hline \multirow{2}{*}{ Grup } & \multicolumn{1}{c}{ Süreç } & $\begin{array}{c}\text { KlinikAralık } \\
\text { (n) }\end{array}$ & $\begin{array}{c}\text { Subklinik Aralık } \\
\text { (n) }\end{array}$ \\
\hline \multirow{3}{*}{ Müdahale Grubu } & Programdan Önce & 11 & 0 \\
& Programdan Sonra & 1 & 10 \\
& İzlemden Sonra & 1 & 10 \\
\hline \multirow{3}{*}{ Kontrol Grubu } & Programdan Önce & 11 & 0 \\
& Programdan Sonra & 11 & 0 \\
& İzlemden Sonra & 11 & 0 \\
\hline
\end{tabular}

Padua Envanterinin kesim noktaları sağlıklı grup için en yüksek puan olarak 21,6; obsesif kompulsif bozukluk klinik vaka grubu için en yüksek puan olarak 66,7; subklinik belirtiler deneyimlenen grup için ise 21,6 ile 66,7 puan arasında olarak belirlenmiştir (Oppen, Hoekstra ve Emmelkamp, 1995). Kesim noktalarına göre katılımciların ön test, son test ve izlem testi ölçümlerinden elde edilen puanların hangi aralığa düştüğü yorumlanmıştır. Müdahale grubu katılımclarının tamamı ön test ölçümünde klinik aralıkta iken, son test ölçümünde ve izlem testi ölçümünde grupta bulunan 10 kişi subklinik aralıkta, 1 kişi ise klinik aralıkta yer almıştır. Kontrol grubunu oluşturan 11 kişi ön test ölçümünde, son test ölçümünde ve izlem testi ölçümünde klinik aralıktadır (Tablo 8). Bu sonuçlar; uygulanan müdahalenin anlamlılığının sadece puan ortalamalarında değil puandan elde edilerek oluşturulan klinik grup aralıklarında da geçerli bir değişime neden olduğunu göstermektedir.

\section{Tartışma}

Bu çalışmada, bilinçli farkındalık temelli bilişsel terapi programının obsesif kompulsif belirtiler üzerindeki azaltıcı etkisini incelemesi amaçlanmıştır. Bu bağlamda bireylerin obsesif kompulsif belirtilerini izleyebilmek için Padua Envanteri kullanılmıştır. Çalışmanın iki hipotezi bulunmaktadır. İlk hipotez, "Bireylerin deneyimledikleri obsesif kompulsif belirti düzeylerinin azalmasında bilinçli farkındalık temelli bilişsel terapi programı etkilidir." Olarak, ikinci hipotez ise "programın etkisi izlem sürecinin tamamlanmasından sonra da devam edecektir." şeklinde oluşturulmuştur.

İlk hipotezin sınanması için yapılan analizlere göre, müdahale grubunun Padua Envanteri ön test ve son test puan ortalamaları arasında istatis- 
tiksel olarak anlamlı bir farklılık bulunmuştur. Müdahale grubu katılımcılarının program tamamlandıktan sonra uygulanan son test ölçümleri, programdan önce uygulanan ön test ölçümlerinden anlamlı derecede düşüktür. Başlangıçta alınan ölçüme göre anlamlı bir azalma gözlenmiştir. Sonuç olarak; müdahale programının bireylerin obsesif kompulsif belirti düzeylerini azaltmada etkili olduğu söylenebilir. Kontrol grubunun ön test ve son test puan ortalamaları arasındaki farklılık incelenmiştir. Yapılan analiz sonuçlarına göre; herhangi bir uygulama yapılmayan kontrol grubunun ön test ve son test puan ortalamaları arasında istatistiksel olarak anlamlı bir farklılaşma görülmemiştir.

İkinci hipotezi sınayabilmek amaciyla grupların son test ve izlem testi puan ortalamaları arasındaki farklılık incelenmiştir. Yapılan analize göre, müdahale grubunun son test ve izlem testi puan ortalamaları arasında istatistiksel olarak anlamlı bir farklılık görülmemiştir. Müdahale grubunun, son test puan ortalamasındaki düşüş, izlem süreci boyunca da korunabilmiştir. Bu doğrultuda, bilinçli farkındalık temelli bilişsel terapi programının, bireylerin obsesif kompulsif belirtileri üzerindeki etkisinin uzun vadede desteklendiği söylenebilir.

Bilinçli farkındalık temelli yaklaşımlar bilişsel terapilerin üçüncü dalgası olarak nitelendirilmekle birlikte literatürde oldukça yenidir. $\mathrm{Bu}$ sebeple bilinçli farkındalık temelli teknikler bilişsel davranış̧̧ı yaklaşım ile birlikte son yıllarda yaygin olarak kullanılmakta ve deneysel olarak araştırılmaya devam edilmektedir (Kabat-Zinn, 2009). Psikoterapi süreci içerisinde bilinçli farkındalık tekniklerinin kullanılabildiği deneysel çalışmaların yapılması, bilinçli farkındalığa dair bilimsel ve aynı zamanda klinik bir arka plan oluşmasına yol açabilmektedir. Literatürde bu yaklaşım yönteminin etkili olup olmadığını test eden araştırma sayısı oldukça sınırlıdır. Bu sebeple bilinçli farkındalık temelli tekniklerin psikoterapi alanında, gerek tek başına gerek diğer yaklaşımlar ile birlikte kullanımının sınandığı bilimsel çalışmalara ihtiyaç duyulmaktadir.

Wilkinson-Tough, Bocci, Thorne ve Herlihy (2010) çalışmalarında, bireysel terapi sürecinde olan bireyler ile uyguladıkları bilinçli farkındalık temelli terapi tekniklerinin obsesif düşünceler üzerindeki etkililiğini test etmiştir. Çalışmanın sonuçlarına göre, katılımcıların ön test puan ortalamsı ile son test puan ortalamsı arasında anlamlı bir farklılık 
gözlenmiştir. Bununla birlikte katılımcıların son test puanları klinik aralığın altına düşmüştür. Bilinçli farkındalık temelli terapi tekniklerinin obsesif düşünceleri olan bireylerde anlamlı düzeyde etkili olduğu sonucuna varılmıştır.

Obsesif kompulsif bozukluk tanısı olan 30 hasta ile gerçekleştirilen bir diğer çalışmada Wahl (2013) tarafından, bilinçli farkındalık ve meditasyon tekniklerinin etkililiği test edilmiştir. Çalışmada, katılımcılar iki gruba ayrılmış, birinci gruptan obsesif düşünceleri ile baş edebilmeleri için meditasyon teknikleri uygulamaları, ikinci gruptan ise baş edebilmeleri için dikkatlerini başka şeylere yönlendirmeleri beklenilmiştir. Çalışmanın sonuçlarına göre, günlük hayatlarında bilinçli farkındalık tekniklerini kullanabilen bireylerin maruz kaldıkları obsesif düşünceleri ile daha iyi baş edebildikleri ve kompulsif davranışa iten dürtüleri erteleyebildikleri belirtilmiştir. Obsesif düşünceleri ile baş edebilmek için dikkatlerini yönlendiren grubun ise düşüncelerini kompulsiyonlara iten dürtülerinin benzer şekilde devam ettiği belirtilmiştir.

Hertenstein ve ark. (2012) çalışmasında bilinçli farkındalık temelli bilişsel terapinin obsesif kompulsif bozukluk belirtileri üzerinde kabul edilebilir ve faydalı bir etkisinin olduğunu belirtmiştir. Bu çalışmada uygulanan programa oldukça benzer olarak uyguladıkları sekiz haftalık program süresince ve sonrasında, katılımcların ifade ettikleri belirti düzeylerinde azalma, şimdiki anda daha aktif bir biçimde var olabilme, onaylanmayan duygulara ilişkin toleransın artması, günlük hayatta ve obsesif kompulsif bozukluk belirtilerine karşı daha sakin bir tutum, uyku kalitesinde artmagibi geri bildirimler elde edilmiştir.

Fairfax ve Barfield (2010) tarafından yapılan çalışmada, çeşitli klinik teknikleri barındıran grup terapisinin obsesif kompulsif belirtiler üzerindeki etkisi sınanmıştır. Çalışmanın sonuçlarına göre, farkındalık temelli tekniklerin obsesif kompulsif belirtiler üzerinde etkili olduğu belirtilmiştir. Bilinçli farkındalık, yönlendirilmiş dikkat benzeri tekniklerin maruz b1rakma ve yanıt önleme tekniğine destekleyici olarak uygulanmasını öneri olarak sunulmuştur. 


\section{Sonuç}

Bilinçli farkındalık temelli tekniklerin obsesif kompulsif belirtileri azaltmadaki etkisini test eden bilimsel yayınların ortak görüşü, bilinçli farkındalık temelli tekniklerin obsesif kompulsif belirtilerin iyileşmesinde geçerli ve faydalı bir yaklaşım olduğu yönündedir. Gerçekleştirilen bu çalışmada temel alınan değişken bireylerin obsesif kompulsif belirti düzeyleridir. Bu nedenle katılımcılardan tanı alacakları bir süreçten geçmeleri beklenilmemiştir. Çalışmanın amacı müdahale uygulanan katılımcıların belirti düzeylerini azaltabilmek olarak belirlenmiştir. Bu sebeple belirti düzeylerini değerlendirebilecek envanter desteği ile devam edilmiştir. Katılımcıların, envanterin yüksek belirtileri temsil eden "klinik" grup aralığında bulunmalarına özen gösterilmiştir. Alternatif bir çalışma obsesif kompulsif bozukluk tanı grubu veya diğer psikiyatrik tanı grupları ile gerçekleştirilebilir.

$\mathrm{Bu}$ çalışmada kontrol grubu bekleme sürecine alınmış ve herhangi bir uygulama yapılmamıştır. Bu deneysel çalışma, plasebo etkisinin de incelenebilmesi amacıyla, kontrol grubunun da belirli bir sürece alındığı bir çalışma ile geliştirilebilir.

Bu çalışmanın, obsesif kompulsif bozukluğun doğasının daha iyi anlaşılması, gerek tedavi sürecinde destekleyici alternatif psikoterapi yaklaşımlarının geliştirilebilmesi gerek obsesif kompulsif belirtilerin sağaltımında yeni bir ekol olarak bilinçli farkındalık temelli yaklaşımların değerlendirilebilmesi adına psikoloji alanına katkı sağlayabileceği düşünülmektedir. Ayrıca, etki kaynağı olarak bilinçli farkındalık müdahalesi hakkında daha net karar vermek amaçlı olarak bir sonraki çalışmalarda yalnızca Bilişsel Davranışçı Terapi müdahalesi olacak bir grubun da desene dahil edilmesi ile yapılacak karşılaştırmaların da faydalı olacağı söylenebilir. 


\title{
EXTENDED ABSTRACT
}

\section{The Effect of Mindfulness Based Cognitive Therapy Program on Reducing Obsessive Compulsive Symptoms}

\author{
Nazire Ayşenur Gündoğan - Gaye Saltukoğlu - Melek Astar \\ Fatih Sultan Mehmet University
}

In the treatment of obsessive compulsive disorder, which shows an increasing prevalence steadily, cognitive behavioral therapy, especially mindfulness based approaches described as the third wave of cognitive therapies, have been shown to be effective in the literature.

Cognitive behavioral therapy approach has included Mindfulness interventions and developed intervention practices for shared use in recent studies (Segal, Williams and Teasdale, 2018; Lucas, Klepin, Porges ve Rejeski, 2018; Wielgosz, et al., 2018; Kabat-Zinn, 2009). Increased interest in the content of mindfulness and its use in psychotherapy have led mindfulness based cognitive therapy's experimental use and its research. Mindfulness definition has three different meanings. It represents a theoretical basis; as well it is used in the sense of practices made to increase mindfulness. It also represents "mindfulness" state defined as a mental and psychological process (Germer, Siegel and Fulton, 2016). Mindfulness state is a mental and psychological process that can be developed with meditation practices (Bishop, et al., 2004). Mindfulness state is defined as to experience only the present moment, to accept the present moment, without being fixated at the experiences and emotions in the past or in the possible future plans. Mindfulness experience includes physical consciousness related to adopt and accept the cognitions of the present moment and the current place (Bishop, et al., 2004; Kabat-Zinn, 2009).

There are publications in the literature that mindfulness based cognitive therapy approach has been useful in the treatment of obsessivecompulsive symptoms. However, the use of mindfulness practices in the 
field of psychotherapy has a very recent history. So, the number of studies is quite limited. The aim of this study is to examine the effects of mindfulness based cognitive therapy program on the obsessive- compulsive symptom levels of individuals.

An experimental study with experiment and control groups, pre-test and post test, and follow up model was designed. The data were collected with "Personal Information Questionnaire" for the personal information, "SLC-90 Symptom Checklist" to examine the inclusion criteria of participants, and "Padua Inventory" to determine the level of obsessive compulsive symptoms.

The study was carried out by the researcher in the province of Istanbul. The participants of intervention and control groups were selected from a pool of 577 people designated as a study group. Pre-interviews were conducted with 50 people who had high scores on the Padua Inventory. Participants were informed about the scheme of the program, expectations from them, participant criteria, attendance and information about volunteering during the pre-interviews and SLC-90 Symptom Checklist were administered. The criteria for the intervention and the control group were as following: not to be in an ongoing psychiatric treatment or psychotherapy process, have not taken alcohol or substance within last six months, have not seen psychiatric treatment and have not used any drug in the last six months, absence of a life long neurological disorder that can prevent participation in the study, absence of signs of suicidal tendencies, absence of personality disorder diagnosis. Besides, as specified by informed consent, participants who have absences of more than two sessions were not included in the study.

Mindfulness based cognitive behavioral therapy program prepared was carried out for a total of eight weeks between the dates of 06 December 2018- 24 January 2019. Once a week, 150 minutes mindfulness based cognitive behavioral therapy sessions were conducted with the intervention group. Intervention has not been made within this period with the control group. Pre-test measurements of the intervention and control groups were taken before the sessions began. The week the sessions of the intervention group were completed, the Padua Inventory was administered as a post-test to both groups. Approximately four months after the completion of the study, follow up measurements were taken. In each 
session of the intervention group, cognitive behavioral practices have been more weighted than mindfulness based approaches. Care was taken to allocate $75 \%$ of the sessions to cognitive behavioral practices and to allocate $25 \%$ of the sessions to mindfulness based approaches.

Study group, selected to form intervention and control groups, consisted of 577 people, 326 women (65.5\%) and 251 men (43.5\%). The scores of the Padua Inventory were sorted from largest to the smallest, interviews were made with high scorers, and those who agreed to participate were randomly assigned to intervention and control groups. The sample consisted of 22 people with equal number of men and women and their mean Padua Inventory scores were calculated as $84.82 \pm 12.50$. As for the study group the mean was $39.87 \pm 21.54$. Study group consisted of people, without any restriction, residing in the province of Istanbul. The age range of the participants was between 19 and 36 , and the mean age was $25.81 \pm 6.03$.

Independent sample $t$ - test was calculated to see whether there was a significant difference between pre-test scores of intervention and control groups. Results showed that there was not a statistically significant difference between the pre-test mean scores of the control group ( $x=83.36)$ and the intervention group $(x=86.27), t(20)=0.54 ; p>0.05$. Also, for age, there was not a statistically significant difference between mean age of the control group $(x=24.27)$ and mean age of the intervention group $(x=25.82), t(20)=0.69$; $p>0.05$. The fact that no statistically significant difference has been found between mean pre-test scores and mean ages of the two groups showed that the age factor will not effect the effectiveness of the therapy program and the effectiveness of the therapy program can be examined in a safe manner. No statistically significant difference was found between women and man ratios of the intervention group, $x=0.091 ; p>0.05$. This result reveals that sex distribution of the intervention group was homogeneous and sex differences will not cause differences in the effectiveness of the therapy program to be applied.

The first assumption for statistical analysis used to determine the effectiveness of the therapy program, the differences between pre- test, post test and follow up test scores and number of participants have to be examined, whether they meet the assumption of normal distribution or not. Because, the number of participants is under 30, Shapiro-Wilk statistics are preferred and seen that all different series distributions are normal 
distribution $(p>0.05)$. Another assumption for the statistic analysis is the assumption of sphericity, that is, the variance of difference between measurements requires being homogeneous. This assumption was examined with Mauchly's Sphericity Test and observed that the variance of differences between measurements was not homogenous; $W=0.293 ; p>0.05$. For this reason, corrections were made according to epsilon values. Since epsilon values were lower then 0.70, Greenhouse-Geisser Correction was preferred. To test whether Padua Inventory pre-test, post test, follow up tests of intervention and control groups' repeated measurement scores differentiated between groups and measurements, the results of two way analysis of variance were evaluated for Greenhouse-Geisser corrected repeated measures.

The overall results showed that the intervention program implemented to the experimental group caused a statistically significant decrease in the obsessive compulsive symptoms of the participants. Follow up test scores showed that experimental group maintained the decreased level of symptoms throughout four months. No significant differences were found between pre and post-test and follow up scores of the control group. According to the results, mindfulness based cognitive therapy could be used as a supportive intervention for the treatment of obsessive compulsive disorder.

\section{Kaynakça / References}

Abramowitz, J., Franklin, M., Schwartz, S., ve Furr, J. (2003). Symptom presentation and outcome of cognitive-behavioral therapy for obsessive-compulsive disorder. Journal of consulting and clinical psychology, 71(6), 1049.

APA (2013). Diagnostic and statistical manual of mental disorders, 5th ed. (DSM5). Washington: DC, American Psychiatric Association.

Atalay, Z. (2018). Mindfulness: Şimdi ve burada bilinçli farkındalık. Psikonet Yayınları.

Barrett, P., Healy-Farrell, L., ve March, J. (2004). Cognitive-behavioral family treatment of childhood obsessive-compulsive disorder: a controlled trial. Journal of the American Academy of Child \& Adolescent Psychiatry, $43(1), 42-62$. 
Beşiroğlu, L.,Ağargün, M. Y., Boysan, M., Eryonucu, B., Güleç, M., ve Selvi, Y. (2005). Obsesif-kompulsif belirtilerin değerlendirilmesi: Padua Envanteri'nin Türk toplumunda geçerlik ve güvenilirliği. Türk Psikiyatri Dergisi, 16(3), 179-89.

Bishop, S. R.,Lau, M., Shapiro, S., Carlson, L., Anderson, N. D., Carmody, J., ..., Devins, G. (2004). Mindfulness: A propose doperational definition. Clinical psychology: Science and practice, 11(3), 230- 241.

Clark, D. (2004). Cognitive-behavioral therapy for OCD. New York: Guilford Press.

Dağ, İ. (1991). Belirti Tarama Listesi (Scl-90-R)'nin üniversite öğrencileri için güvenirliği ve geçerliği. Türk Psikiyatri Dergisi, 2(1), 5-12.

Derogatis, L. R. ve Cleary, P. A. (1977). Confirmation of the dimensional structure of the SCL-90: A study in construct validation. Journal of clinical psychology, 33(4), 981-989.

Fairfax, H., ve Barfield, J. (2010). A group-based treatment for clients with Obsessive Compulsive Disorder (OCD) in a secondary care mental health setting: Integrating new developments within cognitive behavioural interventions - An exploratory study. Counselling $\mathcal{E}$ Psychotherapy Research, 10(3), 214-221.

Germer, C., Siegel, R., ve Fulton, P. (2016). Mindfulness and psychotherapy. New York: The Guilford Press.

Güriş, S. ve Astar, M. (2019). Bilimsel araştırmalarda SPSS ile istatistik. (3.bs.). İstanbul : Der Yayınları.

Hertenstein, E., Rose, N., Voderholzer, U., Heidenreich, T., Nissen, C., Thiel, N., ve Külz, A. (2012). Mindfulness-based cognitive therapy in obsessive-compulsive disorder-A qualitative study on patients' experiences. BMC Psychiatry, 12(1), 185.

Kabat-Zinn, J. (2009). Full catastrophe living: Using the wisdom of your mind and body to face stress, pain, and illness. New York: Delacorte: Bantam Books Trade Paperback Edition.

Kozak, M., ve Foa , E. (1997). Mastery of obsessive-compulsive disorder: A cognitivebehavioral approach: Therapist guide. Oxford: Oxford University Press.

Külz, A., Landmann, S., Cludius, B., Hottenrott, B., Rose, N., Heidenreich, T., Hertenstein, E., Voderholzer, U. ve Moritz, S. (2014). Mindfulnessbased cognitive therapy in obsessive-compulsive disorder: protocol of a randomized controlled trial. BMC Psychiatry, 14(1), 314.

Lucas , A., Klepin, H., Porges, S., ve Rejeski, W. (2018). Farkındalık temelli hareket: çok köşeli bir bakış açısı. Bütünleştirici kanser tedavileri, 17(1), 5-15. 
Olatunji, B., Davis, M., Powers, M., ve Smits, J. (2013). Cognitive-behavioral therapy for obsessive-compulsive disorder: a meta-analysis of treatment outcome and moderators. Journal of psychiatric research, 47(1), 33-41.

Sadock, B., ve Sadock, V. (2008). Kaplan and Sadock's concise textbook of clinical psychiatry. Philadelphia: Lippincott Williams \& Wilkins.

Sakallı, A. K. (2014). Obsesif kompulsif bozukluk tanısı alan hastaların afektif mizaç, kronobiyoloji ve dürtüsellik açısından incelenmesi. İstanbul Üniversitesi, Tıpta Uzmanlık Tezi, 1-26.

Salkovskis, P. (1985). Obsessional-compulsive problems: a cognitivebehavioural analysis. Behav Res Ther, 23, 571-583.

Sanavio, E. (1998). Obsessions and compulsions: The Padua Inventory. Behaviour Research and Therapy, 27, 169-177.

Segal, Z., Williams , M., ve Teasdale, J. (2018). Depresyon için farkındalı̆̆a dayalı bilişsel terapi. Guilford Yayınları.

Şafak, Y., Karadere, M., Özdel, K., Özcan, T., Türkçapar, M., Kuru, E., ve Yücens, B. (2014). Obsesif kompülsif bozuklukta bilişsel davranışçı grup psikoterapisinin etkinliğinin değerlendirilmesi. Türk Psikiyatri Dergisi, 25, 225-233.

Şenormancı, Ö., Konkan, R., Güçlü, O. ve Sungur, M. (2012). Obsesif kompulsif bozukluğun metakognitif modeli. Psikiyatride Güncel Yaklaşımlar, 4, 335-349.

Türkçapar, M. (2009). Klinik uygulamada bilişsel davranışçı terapi: Depresyon. İstanbul: Hekimler Yayın Birliği.

Van Oppen, P.,Hoekstra, R. J., ve Emmelkamp, P. M. (1995). Thestructure of obsessive-compulsivesymptoms. BehaviourResearchandTherapy, 33(1), 1523.

Wahl, K. (2013). Managing obsessive thoughts during brief exposure: an experimental study comparing mindfulness-based strategies and distraction in obsessive-compulsive disorder. cognitive therapy $\mathcal{E}$ research, 37(4), 752-761.

Whittal, M., Thordarson, D., ve McLean, P. (2005). Treatment of obsessivecompulsive disorder: Cognitive behavior therapy vs. exposure and response prevention. Behaviour Research and Therapy, 43(12), 15591576.

Wielgosz, J., Goldberg, S., Kral , T., Dunne, J., ve Davidson, R. (2018). Farkındalık meditasyonu ve psikopatoloji. Klinik psikolojinin yıllık değerlendirmesi. 
Wilkinson-Tough, M., Bocci, L., Thorne, K., ve Herlihy, J. (2010). Is mindfulness-based therapy an effective intervention for obsessive-intrusive thoughts: a case series. Clinical Psychology \& Psychotherapy: An International Journal of Theory \& Practice, 17(3), 250-268.

Williams, M., ve Penman, D. (2015). Farkındalık: Çılgın bir dünyada huzur bulmak için pratik bir rehber. İstanbul: Pegasus.

\section{Kaynakça Bilgisi / Citation Information}

Astar, M., Gündoğan, N. A. ve Saltukoğlu, G. (2020). Bilinçli farkındalık temelli bilişsel terapi programının obsesif kompulsif belirtiler üzerindeki etkisi. OPUS-Uluslararası Toplum Araştırmaları Dergisi, 15(22), 966-993. DOI: 10.26466/opus.618175 